\title{
Comércio e Trabalho:
}

\section{Presença portuguesa nos interiores de São Paulo ${ }^{1}$}

\author{
Trade and Labor: Portuguese Presence in São Paulo Countryside
}

Comercio y Trabajo: presencia portuguesa en el interior de la provincia de São Paulo

Maria Izilda S. Matos ${ }^{2}$

bttps:// orcid.org/0000-0002-4109-3747

Oswaldo Truziri

https:// orcid.org/0000-0002-9046-5092

RESUMO: Lançando mão de um leque de fontes de natureza diversa, este artigo procura rastrear a presença dos imigrantes portugueses no interior do Estado de São Paulo entre o final do século XIX e início do XX, abordando aspectos dessas experiências, e particularizando, no setor comercial, especialmente atividades como a de caixeiros e padeiros.

PALAVRAS-CHAVE: Imigração portuguesa, Interior paulista, Trabalho

\begin{abstract}
By taking advantage of a varied range of historical sources, this article discusses the presence of Portuguese immigrants in the provinces of the State of São Paulo between the late nineteenth and early twentieth centuries. It addresses aspects of their varied work experiences, pointing out, in the commercial sector, especially activities such as travelers-salesmen and bakers.
\end{abstract}

KEYWORDS: Portuguese Immigration, Provinces of São Paulo, Work

\footnotetext{
${ }^{1}$ Este trabalho contou com o apoio do Conselho Nacional de Desenvolvimento Científico e Tecnológico (CNPq) e da Fundação de Amparo à Pesquisa do Estado de São Paulo (FAPESP, proc. 2015/20577-6).

2 Professora titular da Pontifícia Universidade Católica de São Paulo (PUC/SP). Pesquisador do CNPq (1A). Doutora em História e Livre Docente pela PUC/SP. Atua nas seguintes linhas de pesquisa: história cultural, imigração, imigração portuguesa e gênero. Entre várias obras, destacam-se: Por uma possível História do Sorriso: institucionalização, ações e representações (Hucitec, 2019), Cotidiano e cultura: história, cidade e trabalho (E@mansucrito, 2019) e Portugueses: deslocamentos, experiências e cotidiano (EDUSC, 2013).Email: mismatos@pucsp.br

3 Professor Titular do Programa de Pós-Graduação em Sociologia da Universidade Federal de São Carlos (UFSCar). Pesquisador do CNPq (1B). Doutor em Ciências Sociais pela Universidade Estadual de Campinas (UNICAMP). Atua nas seguintes linhas de pesquisa: Sociologia das Migrações, História Social das Migrações e História Regional. Principais obras: Patrícios - sírios e libaneses em São Paulo (UNESP, 2008), Syrian and Lebanese Patrícios in São Paulo: From the Levant to Brazil (University of Illinois Press, 2018) e Italianidade no interior paulista, Café e Indústria. São Carlos (1850-1950) (Unesp, 2016).E-mail: truzzi@ufscar.br
} 
RESUMEN: Utilizando una variedad de fuentes diversas, este artículo busca rastrear la presencia de inmigrantes portugueses en el interior de la provincia de São Paulo entre finales del siglo XIX y principios del XX, abordando aspectos de sus experiencias, y enfocándose en el sector comercial, especialmente actividades como vendedores ambulantes y panaderos.

PALABRA CLAVE: Inmigración portuguesa, Interior de São Paulo, Trabajo

\section{Para citar este artigo:}

MATOS, Maria Izilda S.; TRUZZI, Oswaldo,. Comércio e Trabalho: Presença portuguesa nos interiores de São Paulo. Locus - Revista de história, Juiz de Fora, v.25, n. 2, p.100-120, 2019 E-ISSN: 2594-8296 - ISSN-L: 1413-3024

\section{Introdução}

Esses escritos se propõem a rastrear a presença dos imigrantes portugueses no interior do Estado de São Paulo (séculos XIX e XX), abordando aspectos dessas experiências, particularizando, no setor de negócios, o comércio, especialmente atividades como caixeiros e padeiros. A pesquisa incorporou um amplo e variado grupo de fontes, que inclui: documentação do Departamento de Ordem Política e Social (DEOPS), do Departamento Estadual do Trabalho (DET), do Departamento de Imigração e Colonização (DIC), listas de bordo, almanaques, álbuns, memórias, depoimentos, cartas, entre várias outras. Esse esforço documental se justifica frente às dificuldades de acompanhar os rastros e as trajetórias desses imigrantes. A ideia vigente que o português se nacionaliza na segunda geração e que foi mais facilmente absorvido (entre outros elementos, pela identificação linguística, religiosa e cultural), torna dificultoso diferencia-los da população brasileira, por conta da semelhança dos nomes próprios e de família.

\section{Imigração portuguesa nos interiores de São Paulo: tema e historiografia}

No Brasil, o tema da imigração concentra uma produção ampla, diversificada e enriquecida por abordagens que analisam aspectos diferenciados da questão. Os portugueses constituíram o grupo mais numeroso de imigrantes entrados no Brasil, estimado em 1,9 milhões (1889-1950), com presença por praticamente todo o país. Apesar disso, só recentemente este fluxo tem instigado pesquisadores, sendo que a maior parte das investigações se volta para o Rio de Janeiro, aonde a presença portuguesa foi 
significativa e marcante. Já que a produção historiográfica sobre imigração em São Paulo privilegiou certos grupos, em especial os italianos e japoneses, só ultimamente apareceram trabalhos que investigam os portugueses, tendo como maior foco as cidades de São Paulo e Santos ${ }^{4}$, sendo poucos os trabalhos sobre os lusos no interior do estado de São Paulo.

A imigração portuguesa para o Brasil foi um processo contínuo, que envolveu experiências múltiplas e diversificadas, abarcando várias levas, de diferentes regiões do continente e das ilhas; alguns vieram subsidiados, a maioria por conta própria; alguns chegaram no início do processo (entre fins do século XIX e início do XX), outros após a Primeira Guerra ou durante o período salazarista.

No caso paulista, a imigração pode ser considerada uma temática eleita pela historiografia, particularmente quando intercruzada com outras questões como: cafeicultura, indústria, trabalho e movimento operário. Apesar disso, as experiências migratórias dos portugueses são pouco consideradas, permanecendo a tendência à observação de outros grupos.

Entre 1882 e 1934, dos cerca de quatro milhões de imigrantes que entraram no Brasil, aproximadamente $60 \%$ se instalaram no estado de São Paulo. Grande parte desses veio subsidiada e foi dirigida para os interiores do estado, destacando-se, inicialmente, os italianos. Contudo, após o Decreto Prinetti (1902, proibindo a vinda de italianos subsidiados)5, as entradas desta nacionalidade diminuíram, em favor do aumento das chegadas dos portugueses, espanhóis e japoneses. A maioria dos imigrantes que foi para os interiores acompanhou a expansão cafeeira e ferroviária em direção ao oeste do estado. Neste processo identificam-se três zonas principais: Zona Central (mais antiga, nucleada em Campinas), Zonas Intermediárias (Mogiana e Paulista) e as chamadas Zonas Novas (Araraquarense, Alta Sorocabana e Noroeste) ${ }^{6}$.

Estrangeiros em São Paulo (maiores grupos), 1885-1961

\begin{tabular}{|c|r|r|r|r|}
\hline Anos & TOTAL GERAL & \multicolumn{1}{|c|}{ Portugueses } & \multicolumn{1}{c|}{ Italianos } & \multicolumn{1}{c|}{ Espanhóis } \\
\hline $1885-09$ & 1.059 .199 & $\mathbf{1 3 4 . 5 9 4}$ & 744.244 & 180.361 \\
\hline $1910-34$ & 654.637 & $\mathbf{2 6 3 . 0 6 3}$ & 187.558 & 204.016 \\
\hline $1935-59$ & 311.987 & $\mathbf{1 5 6 . 5 3 6}$ & 90.130 & 65.321 \\
\hline $1960-61$ & 31.665 & $\mathbf{1 4 . 9 8 2}$ & 4.144 & 12.539 \\
\hline Total & 2.057 .488 & $\mathbf{5 6 9 . 1 7 5}$ & 1.026 .076 & 462.237 \\
\hline
\end{tabular}

${ }^{4}$ MATOS, Maria Izilda. Portugueses: deslocamentos, experiências e cotidiano. Bauru: Edusc, 2013.

5 ALVIM, Zuleika. Brava Gente! Os italianos em São Paulo. $2^{a}$ ed. São Paulo: Brasiliense, 1986; TRENTO, Angelo. Do outro lado do Atlântico - um século de imigração italiana no Brasil. São Paulo: Nobel, 1989; VANGELISTA, Chiara. Os braços da lavoura. São Paulo: Hucitec, 1991; TRUZZI, Oswaldo. Italianidade no interior paulista: percursos e descaminhos de uma identidade étnica (1880-1950). São Paulo: Ed. Unesp/FAPESP, 2016; MATOS, Portugueses.

${ }^{6}$ Estima-se que dos quase 2.250.000 imigrantes entrados no estado entre 1890 e 1930, cerca de 58\% foram financiados e em sua maioria passaram pela Hospedaria dos Imigrantes. Nove em cada dez imigrantes saídos desta Hospedaria foram encaminhados para os interiores do estado. Segundo o censo de 1920, dos mais de 1,5 milhão de imigrantes no país, 53\% estavam no estado de São Paulo, destes mais de 800 mil habitavam fora da capital. BASSANEZI, Maria et.al. Atlas da Imigração internacional em São Paulo 1850-1950. São Paulo: Ed. Unesp/FAPESP, 2008. 
Fonte: Departamento de Imigração e Colonização. São Paulo, 1962. p. $44 .^{7}$

Numa análise sobre o perfil dos emigrados portugueses observam-se tendências. A princípio, destacam-se os que vinham por conta própria, geralmente jovens que fugiam do serviço militar, possuíam contatos no Brasil e ocupavam-se em atividades do comércio. Um segundo grupo de homens adultos, muitas vezes casados, artesãos de profissão (pedreiros, ferreiros, alfaiates e sapateiros, entre outros), fixava-se nas cidades. Outro conjunto era dos que vinham subsidiados, majoritariamente embarcados em família, alocados nas lavouras do café. Por fim, uma série de imigrantes que trabalhavam como serviçais e criados, em funções nas cidades ou nos domicílios ${ }^{8}$.

Uma amostragem do ano de 1912 referente às entradas de portugueses pelo porto de Santos registrados nas listas de bordo indica que 63\% não revelaram para onde se dirigiam. Entre os destinos declarados predomina a capital, mas, foram observadas áreas do interior, destacando-se as regiões produtoras de café, como Ribeirão Preto, Jaboticabal, Araraquara, Bauru, Cravinhos, São Simão? .

No levantamento realizado em cartas de imigrantes lusos localizadas nos acervos da Hospedaria do Imigrantes de São Paulo, foram identificadas missivas de várias localidades no interior do estado, o que indica a presença de portugueses em fazendas (Cocais, São João, Nova Lousã) e em cidades como Barueri, Boa Esperança, Campinas, Capão Preto, Espirito Santo do Pinhal, Franca, Jundiaí, Laranjal, Lençóis, Matão, Mococa, Montes Altos, Ourinhos, Pindorama, Pitangueiras, Porto Ferreira, Ribeirão Pires, Ribeirão Preto, Santa Esperança, Santo Antônio da Boa Vista, São Carlos, São Carlos do Pinhal, São João da Boa Vista, São Manuel e Taubaté.

Já em 1920, a maior concentração de portugueses no estado mantinha-se na capital e adjacências (40\%), seguida pela Baixada Santista (13\%). No Oeste paulista, destacavam-se Campinas (4.267 portugueses), São José do Rio Preto (3.507), Araraquara (2.915), Ribeirão Preto (2.706), Barretos (2091), Jaboticabal (2.020) e São Carlos (1.948).

Catorze anos depois, o Recenseamento Demográfico, Escolar e Agrícola-Zootécnico do Estado, realizado em 1934, flagrou portugueses que no interior se faziam presentes em Campinas (3.472), Araraquara (2.411), Ribeirão Preto (1.866), São José do Rio Preto (1.491) e Jaboticabal (1.429). Também eram expressivos em zonas mais à oeste, como Presidente Venceslau (1.752), Marília (1.324),

\footnotetext{
7 Observam-se diferenças numéricas entre as saídas e entradas. A tendência é um número mais elevado das entradas, possivelmente devido aos clandestinos e aos embarques por portos espanhóis. Também cabe lembrar as diferenças na captação e apresentação dos dados entre as estatísticas do Brasil e de Portugal.

${ }^{8}$ LEITE, Joaquim Costa. O Brasil e a Emigração Portuguesa (1855-1914). In: FAUSTO, Boris (org). Fazer a América. São Paulo: Edusp, 2000, p. 193-194. Também SOUSA, Fernando. Os portugueses: de colonos a imigrantes, Anais do VI Seminário e/imigração portuguesa para o Brasil. São Paulo: USP, 2011.

${ }^{9}$ MATOS, Portugueses.
} 
Araçatuba (1.130) e Bauru (1.070), nesta última provavelmente graças ao polo ferroviário ali sediado, que atraiu muitos lusos.

\section{Cafeicultura, terra, trabalho}

Os primeiros imigrantes portugueses que vieram para se empregaram na cafeicultura em São Paulo se estabeleceram na Fazenda Ibicaba (1840), de propriedade do senador Nicolau de Campos Vergueiro. Eram cerca de oitenta famílias que foram contratadas no regime de parceria ${ }^{10}$.

Também foram localizados portugueses na colônia de Nova Lousã, município de Espírito Santo do Pinhal, do comendador João Elisiário de Carvalho Montenegro ${ }^{11}$. O proprietário trouxe 154 imigrantes oriundos de sua terra natal - Lousã, empregando-os sob um sistema de trabalho assalariado.

Em 1867, além de Nova Lousã e Ibicaba, encontram-se referências à presença de portugueses em outras colônias, destacando-se a Fazenda Tatu, de Cândido José da Silva Serra e a Fazenda Boa Vista, de Benedito Antônio de Camargo ${ }^{12}$. Já entre 1888 a 1911, os lusos foram localizados nas colônias de Gavião Peixoto e Bandeirantes ${ }^{13}$.

A imigração esteve diretamente relacionada à expansão cafeeira, os que vieram subsidiados enfrentaram condições difíceis de trabalho nas fazendas. Eram constantes as queixas de não cumprimento dos contratos, autoritarismo e violência, de modo que ao fim do período fixado, muitos buscavam as cidades como alternativa: " $40 \%$ a $60 \%$ abandonavam anualmente as fazendas, era uma resposta às condições miseráveis nas fazendas" ${ }^{\prime 14}$.

No início do século XX, apesar do crescimento da imigração portuguesa para a região cafeeira, a presença destes foi menos intensa nas zonas rurais ${ }^{15}$. Dos portugueses residentes no estado (1934), $70,5 \%$ já viviam nas cidades, sendo que destes $64,0 \%$ na capital. A preferência de se estabelecerem nas

\footnotetext{
10 A fazenda Ibicaba estava localizada no atual município de Cordeirópolis. WITTER, José. Ibicaba: uma experiência pioneira. São Paulo: Arquivo do Estado, 1982, p. 25.

11 SCOTT, Ana Silvia e TRUZZI, Oswaldo. Pioneirismo, disciplina e paternalismo nas relações de trabalho entre proprietário e imigrantes no século XIX: o caso da colónia de Nova Lousã em São Paulo. Anais do VIII Congresso Luso-AfroBrasileiro de Ciências Sociais (Coimbra, 2004), disponível em: < https://www.researchgate.net/publication/28166084>. Acesso em 16 mai. 2018.

12 SCOTT, Ana Silvia. Migrações portuguesas para São Paulo na segunda metade do século XIX: um estudo de caso. Anais do XV Encontro Nacional de Estudos de População (Caxambu, 2006), disponível em: <http://www.abep.nepo.unicamp.br/encontro2006/docspdf/ABEP2006_481.pdf>. Acesso em 16 ago. 2010.

${ }^{13}$ LOBO, Eulália. Imigração portuguesa no Brasil. São Paulo: Hucitec, 2001, p. 23.

14 STOLCKE, Verena. Cafeicultura, Homens, Mulheres e Capital. São Paulo: Brasiliense, 1986, p. 75.

15 BASSANEZI et. al. Atlas, 62.
} 
cidades, possivelmente, se deva a veiculação das condições de trabalho nas fazendas, bem como aos relatos de sucesso em atividades urbanas, com destaque para o comércio ${ }^{16}$.

\section{Cidades: trabalho, ofícios, negócios, indústrias e capitais}

A partir da segunda metade do século XIX, a expansão cafeeira e ferroviária pelos interiores possibilitou o crescimento urbano "semeando" cidades médias e pequenas interior afora. Algumas dessas localidades se tornaram centros regionais e atraíram muitos imigrantes, entre eles, os portugueses que buscavam aproveitar as oportunidades, sendo encontrados exercendo diversos ofícios e serviços como barbeiro, cocheiro, motorista, garçom, pedreiros, pintores, vidreiros, carpinteiros, entre outras funções.

Entre as profissões que predominavam no cenário urbano destacava-se o artesanato autônomo. Muitos portugueses trabalhavam como marceneiros, ferreiros, ourives, relojoeiros, seleiros, calígrafos, tipógrafos, sapateiros, alfaiates, modistas/costureira, bordadeiras, chapeleiros e gravateiros. Dependendo do vulto do negócio, eram auxiliados pelo grupo familiar ou algum conterrâneo ou agregado. O fato de as crianças serem introduzidas desde pequenas no aprendizado e utilizadas como ajudantes de seus pais fez com que muitas destas profissões adquirissem tradição hereditária, passando de geração a geração ${ }^{17}$.

Os imigrantes lusos constituíam redes ${ }^{18}$ de recepção e acolhimento, que ampliavam possibilidades de arranjar emprego nos setores fabris, de serviços, obras públicas e, também, no setor ferroviário, no qual eram entre $16 \%$ e $18 \%$ dos trabalhadores, destacando-se nas funções de feitores e maquinistas ${ }^{19}$.

\footnotetext{
16 Alguns portugueses tiveram acesso a terras, em sua maioria pequenas e médias propriedades. Levantamentos do DET apontam propriedades de portugueses em Araraquara, Atibaia, Bariry, Bauru, Bica da Pedra, Bofete, Brodowsky, Brotas, Campinas, Catanduva, Descalvado, Franca, Ibitinga, Jaboticabal, Joanópolis, Limeira, Matão, Monte Alto, Monte Azul, Olímpia, Orlândia, Pirassununga, Piratininga, Pitangueiras, Piraju, Pederneiras, Rio Preto, S. Cruz da Conceição, S. Rita do Passa Quatro, São Carlos, S. João da Boa Vista, S. João do Rio Pardo, Serra Negra, Sertãozinho, Tabapuã, Taquaritinga, Tietê, Viradouro. A análise comparativa entre 1904/1905 e 1934/1935 permite observar um crescimento do número de propriedades agrícolas nas mãos de portugueses. Nos municípios a sudoeste do estado (regiões de Presidente Prudente, Marília e Bauru), se em 1904/1905 eram de 0,11 a 0,96\% o total de propriedades agrícolas de cada município; entre 1934/1935, tais cifras situavam-se entre 5,06 e 9,73\% do total de propriedades. Bassanezi et. al. Atlas; São Paulo, Boletim do Departamento Estadual do Trabalho (São Paulo, ano 14 (1924), n. 50/51), 221-28. São Paulo, Estatística agrícola e zootéchnica organizada pela Directoria de Estatística, Indústria e Commércio, 1934-1935 (São Paulo, 1936), apud BASSANEZI et. al. Atlas, p. 99. O aumento de propriedades nas mãos de estrangeiros, a partir da década de 1930, foi possibilitado pela fragmentação das fazendas após a crise de 1929. Colonos que tivessem algum pecúlio tiveram oportunidades de adquirir lotes de terra. Maria Campos, Imagens do imigrante português no meio rural paulista. In: ROCHA-TRINDADE, Maria e CAMPOS, Maria Christina S. (orgs). Olhares lusos e brasileiros. São Paulo: Usina do Livro, 2003, p. 73.

${ }_{17}$ Desde pequenos os filhos eram iniciados na rotina do trabalho. As crianças realizavam pequenos trabalhos, vendiam jornais, entregavam mercadorias, recados, cartas, eram engraxates, auxiliares em serviços domésticos, lojas e armazéns. A necessidade de as crianças desde cedo se engajarem no trabalho, quer seja casual ou nas fábricas, fruto das necessidades das camadas pobres imigrantes era visto como uma possibilidade de obtenção de um ofício.

18 TRUZZI, Oswaldo. Redes em processos migratórios. Tempo Social, Revista de Sociologia da USP. São Paulo, v. 20, 2008, p. 199-218.

${ }^{19}$ LANNA, Ana Lucia D. Trabalhadores das ferrovias: A Companhia Paulista de Estrada de Ferro, São Paulo, $1870-1920$. Varia História. Belo Horizonte, vol. 32, n. 59, 2016, p. 505-545. Além disso, também Carvalho, ao estudar a greve de 1914 ,
}

Locus: Revista de história, Juiz de Fora, v.25, n. 2, p.100-120, 2019

E-ISSN: 2594-8296 - ISSN-L: 1413-3024 
Aparecem referências a portugueses em investimentos industriais, empresas de transportes e serviços urbanos (gás, luz, entre outras), companhias de seguros e bancos (encarregados de remessas) e propriedades urbanas. Esses imigrantes que se engajavam em atividades industriais eram naturais do meio urbano em sua terra natal, tinham alguma instrução, experiência no comércio e/ou na manufatura. Alguns traziam reservas de capital, em espécie ou em mercadorias, ou vinham com a proposta de instalar uma filial de alguma empresa no Brasil ${ }^{20}$.

$\mathrm{Na}$ análise do Almanach Illustrado de Ribeirão Preto (1913) identificou-se o português Antônio Gomes Duarte como industrial do ramo de "café e fubá", atuante no beneficiamento e na produção de máquinas para moagem. Já no Álbum da Colônia Portuguesa no Brasil ${ }^{21}$ apareceram listados industriais portugueses na cidade de Taubaté: J. Carvalho Viana (calçados) Francisco Fernandes Viana (louças), Alfredo dos Santos (máquinas), Francisco Nunes (artigos para confeitarias) e José Rocha Moreira (chapéus) $^{22}$.

Emblemática foi a trajetória de Antônio Pereira Ignácio, nascido em 1874 em Baltar, e que chegou ao Brasil com onze anos de idade. A família se instalou em Sorocaba, onde aprendeu o oficio e trabalhou como sapateiro, exercendo, posteriormente, a mesma função em São Paulo (Casa Ferreira Junior \& Saraiva) e no Rio de Janeiro. Aos 18 anos, estabeleceu-se em São Manoel do Paraiso e mais tarde em Sorocaba, onde criou uma pequena fábrica de calçados. Mudou-se para Botucatu, onde instalou um armazém, vendeu esse estabelecimento e montou uma fábrica de descaroçar algodão em Boituva (1899). Frente ao sucesso da empreitada, instalou duas filiais (em Tatuí e Conchas). Era um ramo promissor, devido ao crescimento do setor industrial têxtil de algodão na capital e nos interiores.

Em 1905, Pereira Ignácio regressou a Sorocaba e em sociedade com João Reynaldo de Faria, ampliou seus negócios com a produção de óleo de algodão e entrou para o ramo industrial têxtil (Fábricas de tecidos São Bernardo e Luzitania, Fábrica Bom Retiro, Cia Fabril Paulistana e Votorantim). Também foi um dos fundadores da Companhia Telefônica Sul Paulista que daria origem à Rede Telefônica Bragantina e da Usina de Força e Luz do Pilar ${ }^{23}$.

indica que "na história da Noroeste do Brasil foi comum a designação do cargo de feitor de turma para portugueses" [CARVALHO, Diego. Trabalho e conflito na Noroeste do Brasil. A greve dos ferroviários de 1914. São Paulo: FFLCH-USP (dissertação de mestrado), 2009, p. 72].

20 Observa-se que muitos dos empresários eram estrangeiros; encontra-se nomes e sobrenomes de italianos, alemães, espanhóis, sírio-libaneses e outros nos mais diversos setores da indústria, contudo, no caso dos portugueses a identificação por nomes não se torna viável, devido à similaridade com os nomes de brasileiros.

${ }^{21} \mathrm{O}$ Álbum da Colônia Portuguesa no Brasil (1929) foi organizado pelo jornalista luso Teófilo Carinhas. A publicação conta com 670 págs., destaca a presença portuguesa na Capital Federal e nos Estados, incluindo São Paulo, capital e cidades do interior (Campinas, Taubaté, Ribeirão Preto). O álbum caracteriza-se por textos ufanistas, destacando a elite portuguesa estabelecida e contempla anúncios. PEREIRA, Maria A. F. Portugueses no alto comércio santista no início da República Velha. In: MATOS, Maria Izilda e SOUSA, Fernando. Deslocamento \& histórias: os portugueses. Bauru, EDUSC, 2008, p. 119-130.

22 CARINHAS, Teófilo. Álbum da Colônia Portuguesa no Brasil. 1929.

${ }^{23}$ Impressões do Brazil no Século Vinte. Londres: Lloyd's Greater Britain Publishing Company, Ltd, 1913. 
Na sua trajetória como empresário, adquiriu a fábrica de cimento Rodovalho, fundou a Fábrica de Vidros Lamina, tornou-se o maior acionista da Sociedade Votorantim (1918), que inclui os ramos de tecidos, cimento, cal, papel, siderurgia, tijolos refratários e da via Férrea Votorantim. Tornou-se benemérito de várias instituições em São Paulo e em Portugal ${ }^{24}$.

No setor industrial, também merece menção Manuel Rodrigues Tavares de Almeida, natural de Aveiro (1930), que emigrou aos 19 anos e em São Paulo foi balconista em padaria, taxista, panificador e corretor de imóveis. Em 1969, adquiriu em Piracicaba sua primeira empresa, a Tatuzinho-aguardente. Ampliou seus negócios na área com a produção das caninhas, que foram acrescidas da Agropecuária São Pedro, Água Poá e Cerâmica Tatuzinho. Seus negócios também incluíam hotéis (Hotel Casa Grande do Guarujá-SP), bancos (Banco Luso Brasileiro), Motocana máquinas e implementos agrícolas, São Paulo Tratores e a Destilaria Vista Alegre (Itapetininga), constituindo um conglomerado - o grupo Tavares de Almeida.

Em Campinas, destacou-se o português Victorino Pinto Nunes, que em 1885 foi posicionado entre as dez maiores fortunas de cidade e região. Era um dos maiores acionistas da Companhia. Paulista de Estradas de Ferro, também da Companhia Campineira de Iluminação e Gás, além de possuir vários imóveis na cidade. Nos anos de 1870, tornou-se o nono capitalista com maior volume de empréstimos na cidade. O inventário deste capitalista (falecido em 1881) apresenta detalhes dos bens, montante de recursos e relação de devedores ${ }^{25}$.

Outro ramo de possibilidades comerciais e empreendedorismo era o da construção civil. Com a intensificação da expansão urbana e populacional cresceram a necessidade por moradias e prédios públicos, o que gerou aumento na demanda de materiais para obras. Dessa forma, pode-se observar portugueses comercializando tais produtos (pedras, cimento, tijolos entre outros artigos). Os lusos também se destacaram como empreiteiros, construtores e trabalhadores nesse ramo.

Lançaram-se igualmente no ramo das serrarias, na produção de janelas, portas, portões, assoalhos e forros para tetos, também na fabricação e comercialização de pregos e móveis de qualidade. Eram várias as serrarias que pertenceram a lusitanos em Ribeirão Preto e, de modo geral, em todo o interior paulista. Provavelmente os portugueses neste setor puderam se beneficiar de suas relações com conterrâneos empregados nas ferrovias, já que, em seguida ao desmatamento, as toras eram trazidas pelas vias férreas às serrarias, a cujos pátios, não raro, chegavam trilhos próprios desviados da linha

\footnotetext{
${ }^{24}$ DEAN, Warren. A industrialização de São Paulo: 1880-1945. São Paulo: Difel, 1971, p. 111 e segs; SCANTINBURGO, João. José Ermírio de Moraes: o Homem - a Obra. São Paulo: Cia. Ed. Nacional, 1975, p. 108 e segs.

25 SABARIM, Fernanda. Capitalistas em Campinas 1873-84. FEA/UNICAMP, TCC em economia, 2010. 
principal. Em São Carlos, por exemplo, o português Francisco Ferreira fundou (1910) a serraria Santa Rosa - uma das maiores do interior ${ }^{26}$.

Ainda exemplar foi a trajetória do Sr. Emilio na área de cerâmicas e olarias:

Em 1919 emigrou para o Brasil sozinho. Durante alguns anos foi barbeiro, mas sua principal atividade foi no ramo da olaria. Trabalhou alguns anos no Sul do país em uma cerâmica de um de seus tios e depois de casado conseguiu montar uma cerâmica própria com a ajuda da esposa e do sogro em Tambaú/SP... foi presidente da Cooperativa dos Produtores de Cerâmica ${ }^{27}$.

Outro setor com presença de portugueses e vinculado à construção civil era o das vidraçarias, nele se produziam vidros para portas e janelas, espelhos, cristais, vidros em geral e molduras para quadros.

\section{Crescimento urbano: o comércio como campo de possibilidades}

O crescimento urbano nos interiores esteve vinculado à expansão cafeeira e ferroviária. Os trilhos não só transportavam rápida e eficientemente o café, também possibilitaram a chegada dos imigrantes ${ }^{28} \mathrm{e}$ ampliaram os circuitos de trocas mercantis e redes de negócios. O setor oferecia condições de ganhos e oportunidades de melhoria de vida. Assim, os portugueses identificaram no comércio um campo de possibilidades. No Estado de São Paulo, os portugueses foram a maioria dos comerciantes entre os estrangeiros, em número superior aos sírios libaneses e italianos ${ }^{29}$.

A presença dos lusos no comércio ocorreu em vários setores comerciais. Alguns em negócios de grande porte, como Francisco Gonçalves Ferreira Novo, já mencionado. Sua empresa com sede em Campinas era atuante nos ramos de negócios do café e importação em geral, mantendo conexões com

\footnotetext{
26 Em 1915, a Serraria Santa Rosa chegou a empregar cerca de 100 homens que trabalhavam com 400 juntas de bois puxando madeira do mato em direção a ramais ferroviários, além de 60 operários internos à própria serraria. (TRUZZI, Oswaldo. Café e indústria. São Carlos, 1850-1950. São Paulo: Imprensa Oficial do Estado e São Carlos: EdUFSCar, 2007, p. 169).

27 CAMPOS, Maria Christina. Imagens do imigrante português no meio rural paulista. In: ROCHA-TRINDADE e CAMPOS, Olhares lusos e brasileiros, p. 86.

${ }^{28}$ Em 1886, os estrangeiros em Ribeirão Preto constituíam 7,3\% do total de habitantes, sendo o grupo composto por apenas 761 pessoas. Desse total, 46,2\% eram austríacos, 20,7\% eram italianos e 18,4\%, portugueses. Em 1902, os estrangeiros passaram a compor $62 \%$ da população, totalizando 33.119 imigrantes. Essa população imigrante era representada por $83,7 \%$ de italianos, $7,9 \%$ de portugueses e $5,1 \%$ de espanhóis, as três nacionalidades mais representativas. SANTOS, Jonas. Imigração e ascensão social em Ribeirão Preto entre o final do século XIX e meados do XX. Caxambu: Anais do XV Encontro Nacional de Estudos Populacionais, ABEP, 2006.

${ }^{29}$ Censo de 1940. São Paulo, Empresas com atividades no comércio de mercadorias e capital realizado distribuído pela nacionalidade dos subscritores de capital. Censo de 1950. São Paulo, Nacionalidade dos proprietários e sócios de firmas individuais e sociedade de pessoas do comércio varejista segundo gênero de comércio. Censo de 1950. SP, Nacionalidade dos proprietários e sócios de firmas individuais e sociedade de pessoas segundo gênero de serviços.
} 
o porto de Santos30. Também atuaram no setor têxtil, de fios, artefatos de tecidos e vestuário, armarinhos, chapéus e calçados (sapatarias) ${ }^{31}$.

Pela análise da documentação (imprensa, álbuns e almanaques), pode-se observar que outros se especializaram na venda de produtos portugueses (vinhos, azeites, azeitonas, conservas, entre outros), o que denota o interesse por essas mercadorias, inclusive pela presença de muitos consumidores lusos. $\mathrm{O}$ português Francisco Joaquim Duarte, estabelecido em Campinas, destacava-se no setor de importação, exportação, comissões e consignações, proprietário de amplo armazém de vinhos que abastecia várias cidades do interior.

A ampliação destas atividades e estabelecimento do comércio tendeu a acompanhar a expansão da malha urbana-ferroviária para as cidades do oeste paulista. Pelos anúncios e outras referências (álbuns e almanaques) observa-se que alguns atuavam no atacado (grossistas) ${ }^{32}$, trabalhavam por comissão com gêneros nacionais (café e fubá) e produtos estrangeiros. Majoritariamente, os negócios dos lusos se identificavam como armazéns de secos e molhados, mercado elástico e com flexibilidade de produtos variados, bebidas, comestíveis, gêneros da terra e do estrangeiro. Muitos se mantiveram articulados a casas comerciais na Capital e no porto de Santos, como representantes e trabalhando no sistema de consignação, atuando por comissão ou por conta própria.

O português Manoel Antônio de Matos chegou ao Rio de Janeiro com apenas 11 anos de idade e empregou-se no comércio. Aos vinte anos, estabeleceu-se em São Carlos com um negócio próprio, casou-se em uma das mais abastadas famílias de fazendeiros da região. A partir de então, passou a exercer diversos cargos públicos, entre eles o de juiz de paz e de intendente municipal ${ }^{33}$.

Já José Pereira de Andrade, vice-cônsul de Portugal em Campinas (1898-1916) dedicava-se ao comércio de secos e molhados em sociedade com José Gomes de Faria. Outro destacado comerciante era Arthur Moreira da Rocha Brito, que foi vice-presidente da Beneficência Portuguesa de Campinas, cujo armazém de secos e molhados oferecia sortimento variado de produtos, que se propunha a remeter as encomendas a "qualquer ponto da estrada de ferro".

Destacavam-se entre os principais negociantes de Taubaté, os portugueses Joaquim Mendes Castilho (molhados), F. Sousa Castro (Farmácia), M. Silva e Cia (fazendas), Antônio Barreira Passos (artigos dentários, armarinhos e fazendas), Antônio Rodrigues de Miranda (molhados), Alfredo Ferreira de Matos (café e bar), Aécio dos Santos (cereais), Manoel dos Santos (refinação de açúcar), Arnaldo Pinto Guedes (calçados), Correia Gomes \& irmãos (armarinhos e fazendas), Adelino Figueiredo Pinto

\footnotetext{
${ }^{30}$ Gazeta de Campinas, 1877.

${ }^{31}$ LOBO, Imigração portuguesa, p. 287-295.

32 Os termos negociante e comerciante explicitam maior prestígio, possível dono do negócio. Já caixeiro, viajante e mascate eram os empregados no setor do comércio.

33 DAMIANO, Octavio. Caminhos do tempo. São Paulo: Imprensa Oficial do Estado e São Carlos: EdUFSCar, 2004, p. 166.
}

Locus: Revista de história, Juiz de Fora, v.25, n. 2, p.100-120, 2019 
(automóveis), M. Lopes Valente (drogaria), Inocêncio Domingues (molhados), J. Miranda \& Cia (molhados) $)^{34}$.

Entre os comerciantes portugueses identificados em Ribeirão Preto, encontra-se várias referências à Casa Pereira. Outros lusos reconheciam as novas possibilidades e diversificavam seus negócios. Este foi o caso de Antão Adelino Mendes (Presidente da Sociedade Beneficência Portuguesa de Ribeirão Preto) que tinha lojas de fazendas e que se tornou proprietário do Hotel do Comércio, em 1918. Já Alfredo Condeixa (membro de destaque na Beneficência Portuguesa), era comerciante do ramo de secos e molhados, encontrando-se instalado na cidade desde 1915.

Em outras cidades merece menção os comerciantes portugueses Alfredo Joaquim Goes (Araraquara), Casa Ferreira (São João da Boa Vista) e Avelino Sampaio \& Cia (Piracicaba). Também encontram-se referências à presença portuguesa no comércio de Franca, atuando no agenciamento do café, com produtos de vestuário e outras mercadorias como ferragens, fazendas, tintas, armas, arreios e artigos para a lavoura ${ }^{35}$.

Várias firmas importadoras estabelecidas em São Paulo ou em Santos ${ }^{36}$ como Bento de Souza e Cia., C. Costa e Cia., Souza Santos e Cia., Luiz França dos Santos e Cia tinham esquemas organizados de vendas para os interiores, através de caixeiros-viajantes que atendiam consumidores ou lojas, ou através de comissões e representações.

Merece registro o português João Alves Veríssimo, que iniciou sua vida de comerciante em Nova Granada. Posteriormente, desenvolveu a atividade comercial no ramo de atacado de alimentos (a empresa Alves Veríssimo \& Cia possuía unidades em Votuporanga, Presidente Prudente, São José do Rio Preto, Campinas Londrina, Ourinhos, Marília, Arapongas, Cornélio Procópio, Goiânia, Paranavaí, Belo Horizonte, Uberlândia e Maringá). Fundou (com os seus sobrinhos João Alves Veríssimo e Avelino Veríssimo) os Supermercados e Shopping Center Eldorado, seus negócios incluíam o Moinho Paulista, Vega (conservas), Crovel (óleos) e a rede de atacado.

Cabe registro a trajetória de Manuel da Silva Sé, natural da ilha da Madeira (1915), que chegou ao Brasil em 1939 e se estabeleceu em São José do Rio Preto. Em 1954, em sociedade com Antônio Gonçalves instalou a Empresa Gonçalves Sé S/A - Comércio e Importação. A empresa atuava na capital e possuía lojas em 16 municípios paulistas, além de Londrina. Em 1975, a família Sé comprou a parte de seus sócios e a partir de então passou a denominar-se Sé S/A Comércio e Importação, permanecendo até a atualidade.

\footnotetext{
${ }^{34}$ CARINHAS, Álbum.

35 Impressões do Brazil.

${ }^{36}$ FRUTUOSO, Maria Suzel G. A presença portuguesa do comércio de Santos, In: MATOS e SOUSA, Deslocamentos \& Histórias, p. 141-54.
} 
A expansão das cidades e o aumento considerável da população imigrante geraram novos hábitos, as práticas alimentares se alteraram, tornando-se mais variadas, diversificando os produtos e ampliando as oportunidades no comércio destes gêneros. Os portugueses se destacaram no comércio à retalho com negócios de pequeno e médio porte, na maioria unidades familiares. Procurando trabalhar com um custo operacional mínimo, aproveitavam o quarto da frente de suas próprias casas para estabelecer pequenos armazéns, mercearias, açougues, adegas, leiterias, quitanda de frutas e legumes, vendas, botequins, tabernas, bares; também alfaiatarias, lojas de roupas, tecidos, armarinhos e miudezas, ferragens, louças, vidros. Entrecruzando o público e o privado, o negócio e o lar, a família trabalhava arduamente no balcão, os poucos auxiliares eram também portugueses, em geral recém-chegados que se colocavam sob a tutela de conterrâneos (não faltam referências a filhos e a sobrinhos) ${ }^{37}$. Tal tipo de arranjo parece ter se prolongado por décadas a fio, pois era comum que famílias portuguesas já instaladas atraíssem parentes jovens (sobretudo homens), enviando-lhes cartas de chamada.

Eu cheguei em 1953 ... vim para Presidente Prudente. O meu tio que me mandou vir, só se podia entrar no Brasil através de uma carta de chamada, que era uma carta compromisso, elaborada no Consulado (...) O caso do meu tio, porque era meu padrinho, ele se responsabilizava por essa pessoa, e durante dois anos ele era obrigado a dar toda a assistência, inclusive, se fosse o caso, se a pessoa não se adaptasse, era obrigado a colocá-lo novamente na terra de origem; não foi o meu caso ${ }^{38}$.

Entre as diferentes categorias de vendedores ambulantes, que retiravam sua sobrevivência do comércio nas ruas, os portugueses se encaixaram entre aqueles que ofereciam gêneros fundamentais à rotina doméstica, comercializados em pequenas quantidades. Utilizando-se de carrocinhas de madeiras, ofereciam verduras, frutas, flores, ovos, aves, pão e também lenha. $\mathrm{Na}$ possibilidade de concentrar a produção e a comercialização, os lusos dominavam o comércio nas feiras livres; contudo, os rendimentos eram incertos, já que vários produtos estavam sujeitos à sazonalidade e aos efeitos das intempéries naturais como geadas, chuvas de granizos e secas.

\section{Caixeiros: cotidiano, trabalho e exploração}

\footnotetext{
${ }^{37} \mathrm{O}$ balcão era o palco privilegiado das manifestações de antilusitanismo, convivendo-se com as tensões em torno das cobranças, atrasos e recusas no pagamento das contas consideradas abusivas, hostilidades, muitas vezes brigas, denúncias à polícia, provocações e insultos. Estas tensões contribuíram para a constituição das representações do português como explorador, sovina, açambarcador e falsificador (denúncias de fraudes). As infrações à economia popular denotavam a atuação dos imigrantes nas atividades comerciais (açougues, padarias, armazéns, adegas, botequins, restaurantes, confeitarias e pastelarias, quitandas, leiterias). Alguns destes estabelecimentos eram familiares e para a sua instalação se aproveitava um quarto da frente da própria casa; outros, mais amplos, mostravam uma ascensão no ramo comercial.

38 SILVA, Alcides. Roteiro Histórico: uma cidade e uma instituição. Bauru: Tipografia Comercial, 1957, p. 96.
} 
Os lusitanos eram majoritários entre os empregados no comércio, alguns vinham muito jovens (em geral próximo dos 14 anos) fugindo do serviço militar. As famílias se empenhavam em enviar seus filhos, mesmo se utilizando de engajadores e agentes, comprometendo-se com pagamentos para liberar das obrigações legais. A busca de fortuna e prestígio impulsionava esses jovens a atravessar o Atlântico e se embrenharem pelos interiores do estado de São Paulo ${ }^{39}$. Os jovens eram chamados por conterrâneos, familiares ou conhecidos, estabelecendo expansão capilar via redes de chamada.

A preferência por portugueses devia-se por serem considerados mais estáveis e submissos, menos exigentes frente às condições de trabalho (longas e árduas jornadas, acumulo de funções, sem repouso semanal), flexíveis para realizarem várias funções, de confiança, dedicados e leais.

Era comum que grandes firmas de atacadistas portuguesas, como J. Alves Veríssimo, Dias Pastorinho, Dias Martins, J. Pires, ampliassem seus distribuidores e representantes comerciais lançando mão de conterrâneos recrutados em Portugal, tendo a vinda viabilizada através das chamadas. Os recém-chegados iniciavam suas atividades nos armazéns das empresas, depois podiam exercer funções de venda externa, como caixeiro-viajante e, alguns, posteriormente, poderiam se estabeleceram com negócios próprios, como é o caso do Sr. José Lopes que constituiu uma empresa de empacotamento e venda de arroz na cidade de Marília ${ }^{40}$.

Outros relatos destacam o caso de um jovem de 19 anos, filho caçula, que trabalhou por três anos em Portugal como aprendiz em uma pequena mercearia de parentes, sem nada ganhar além de experiência:

(...) tomou conhecimento de que no Brasil as empresas J. Alves Veríssimo e Dias Martins estavam contratando pessoas para trabalhar no comércio varejista, e as pessoas que eram procuradas tinham que ter certo conhecimento de comércio. Ficou sabendo desse emprego através de um agenciador da família Veríssimo ${ }^{41}$.

Os ditos engajadores percorriam aldeias e cidades procurando atrair uma mão-de-obra minimamente treinada nas lides comerciais. Em depoimento, a viúva de um imigrante português se queixa das falsas promessas feitas por agenciadores:

39 O jovem era preparado para emigrar, a família investia no processo de aprendizagem (ler, escrever e contar, dotes caligráficos) que permitia constituir um capital humano, criando competência para melhor inserção na sociedade de acolhimento na perspectiva de um futuro melhor, com retorno financeiro e reconhecimento social. Algumas associações portuguesas no Brasil mantinham escolas, como a Câmara Portuguesa de Comércio de São Paulo, que criou a Liga Propulsora da Educação, em Portugal. (ALVES, Jorge. Os Brasileiros. Emigração e Retorno no Porto Oitocentista, 1994; RODRIGUES, Henrique. Emigração de jovens e correspondências. Cartas do Brasil para Portugal no século XIX. Navegar, vol. 3, 2017. Disponível em: <http://www.labimi.uerj.br/navegar/edicoes/05/Navegar_5_completa.pdf>. Acesso em 12 jun. 2018).

40 MATTOS, Carlos. A presença dos patrícios no Oeste Paulista: portugueses em Marília. Marília: UNESP, dissertação de mestrado, 2003.

${ }^{41}$ SILVA, Roteiro Histórico, p. 96. 
(...) necessitava de maneira urgente de mão de obra como a dele. Pessoa que soubesse usar a cabeça, pois seu marido era o encarregado de todas as contas da mercearia (...) meu marido veio para o Brasil trabalhar na J. Alves Veríssimo para usar a cabeça. Pois descarregava caminhão todos os dias. Vários sacos de mercadorias em sua cabeça, eram retirados das carrocerias dos caminhões e empilhados nos depósitos da empresa ${ }^{42}$.

A maior parte dos portugueses do setor comercial trabalhavam arduamente, às vezes em labores brutos (como o de carregar e descarregar cargas). Também as padarias funcionavam 7 dias por semana e por quase 20 horas diárias, oferecendo pão quente desde as 5 horas da manhã. Tais práticas foram difundidas especialmente nas padarias de propriedade dos portugueses, que também inovaram na organização do negócio ao incorporarem vários sócios que se revezavam em diferentes turnos.

A maior parte dos portugueses do setor comercial trabalhavam arduamente, às vezes em labores brutos (como o de carregar e descarregar cargas), com o tempo, alguns se tornaram caixeiros-viajantes e passavam frequentar o interior paulista, viajando de trem e mais tarde, de carros.

O cotidiano de trabalho desses lusos era árduo, enfrentavam uma rotina exaustiva (jornadas de até 16 horas/dia, das 7 da manhã até altas horas da noite), insalubre e mal remunerada, marcada pelo autoritarismo dos patrões, pois o controle era rigoroso ${ }^{43}$. Os caixeiros e caixeirinhos portugueses, permaneciam nos domicílios e negócios de parentes e patrões, arcando com os afazeres muitas vezes sem nada receber; outras vezes, parcamente remunerados ou submetendo-se a pagamentos incertos, recebendo somente roupa, alimentação e morando sob o mesmo teto do patrão, até embaixo dos balcões e em cima dos sacos. Paternalismo e exploração caracterizavam estas relações; alguns se rebelaram, outros fugiam, podendo-se também observar um alto índice de caixeiros celibatários, pois devido aos parcos ganhos não conseguiam condições de se casar.

Acompanhando a organização da categoria em cidades como Rio de Janeiro ${ }^{44}$, Belém do Pará ${ }^{45}$ e Santos, os caixeiros tiveram ações combativas, levando à frente suas reivindicações, para tanto buscaram a coesão de "classe caixeiral", na intenção de alcançar as mínimas condições de trabalho e regulamentação. Vários jornais e periódicos (inclusive o da categoria “O Caixeiro”) observavam a exploração dos trabalhadores no comércio, denunciando as péssimas condições de trabalho e solicitando providências das autoridades. A principal bandeira de luta da categoria era a questão da

42 SILVA, Roteiro Histórico, p. 103.

${ }^{43}$ FRANCO, Jaime. A Beneficência: Memória Histórica da Sociedade Portuguesa de Beneficência e Contribuição para a História de Santos. São Paulo: Gráfica da Revista dos Tribunais, 1951, p. 134-137.

44 POPINIGIS, Fabiane. As sociedades caixeirais e o 'Fechamento das Portas' no Rio de Janeiro (1850-1912). Campinas: Cadernos AEL, v.6, n.10/11, 1999.

${ }^{45}$ CARVALHO, Marcos. Os caixeiros e a imprensa lusa em Belém do Pará. In: MENEZES, Lená e SOUSA, Fernando (Orgs.). Brasil-Portugal: pontes sobre o Atlântico Múltiplos olhares sobre a e/imigração. Rio de Janeiro: EdUERJ, 2017, p. 95-108.

Locus: Revista de história, Juiz de Fora, v.25, n. 2, p.100-120, 2019 
jornada de trabalho (fechamento às oito horas da noite nos dias da semana) e garantia do descanso semanal aos domingos.

Em Ribeirão Preto, a Sociedade Protectora dos Empregados do Commercio ${ }^{46}$, atuante desde 1910, assumiu a representação dos caixeiros, sendo presidida por Antônio dos Santos Martins, ele próprio caixeiro guarda-livros.

A formação na função se fazia na prática cotidiana, aprendia-se matemática, contabilidade, domínio da escrituração comercial e outras especificidades do ramo, até idiomas, quando necessário. A profissão de caixeiro se desdobrava em uma hierarquia funcional: caixeiro de balcão, caixeiro com prática de vendas, caixeiro de fora (vendas exteriores), caixeiro viajante, caixeiro de escritório (encarregado das cartas, faturas, compras e vendas), guarda-livros (contabilidade) ou primeiro caixeiro (fiscalização escrituração e do caixa, realização de pagamentos e cobranças). Quando o comerciante era absenteísta, alguns caixeiros exerceram a função de gerente, adquirindo autonomia na condução dos negócios, aspirando até tornarem-se sócios-gerentes.

Observam-se notícias eventuais de caixeiros que assumiram os negócios após a morte do proprietário, administrando para viúva e herdeiros, outros que se tornaram donos e outros ainda que se casaram com a filha do patrão. Contudo, foram poucos os caixeiros que conseguiram expressão nos negócios, ao final de vários anos de trabalho, embora alguns pudessem eventualmente começar um negócio próprio, com o apoio do patrão.

A trajetória de Albano José de Carvalho é ilustrativa. Nascido na região do Douro, veio para o Rio de Janeiro com apenas 10 anos de idade, em 1879. Após trabalhar por um período no Rio, empregou-se como auxiliar de escritório em Cravinhos e, um ano depois conseguiu se estabelecer em Ribeirão Preto, com uma casa de artigos de couro. Participou da fundação da Associação Comercial e Industrial local (1904), presidindo-a em 1912. Dois anos mais tarde, integrou o time de fundadores de uma das mais importantes empresas de Ribeirão Preto, a Companhia Cervejaria Paulista, da qual foi seu primeiro gerente $^{47}$.

Cabe lembrar a trajetória dos Irmãos Ramos, nascidos em Chaves, Trás-os-Montes. João Batista (1939) chegou em 1955, Antônio (1942) em 1959 e Frederico em 1962. Vieram para escapar ao serviço militar, através de cartas de chamada dos tios, que os introduziram no mercado de trabalho. Antônio

\footnotetext{
46 As entidades de auxílio ou socorros mútuos surgiram devido à inexistência e/ou carência no sistema de seguridade social. Assim, elas buscavam assistir nos cuidados de saúde, garantir o sustento frente à impossibilidade de trabalho, zelar pela família dos que faleciam, cuidar/apoiar no funeral, além de prestar serviços jurídicos. Necessariamente, não arcavam com todas essas funções, algumas ofereciam um tipo de assistência específica, sendo que outras mutuais chegaram a construir hospitais, ainda hoje atuantes na cidade de São Paulo. (FONSECA, Vitor. Imigração: Identidade e Integração,1903-1916. In: MATOS e SOUSA, Deslocamentos \& Histórias).

47100 anos da ACIRP. Ribeirão Preto: São Francisco Gráfica e Editora, 2004, p. 232.
} 
dos $\operatorname{Ramos}^{48}$ iniciou como estoquista e depois se tornou caixeiro viajante da empresa de autopeças Russo Greco. Relata que fazia viagens de até 90 dias, em trabalho que exigia dedicação e ousadia, para enfrentar estradas de terra esburacadas e lamacentas, carregar catálogo pesado, mercadorias e amostras. Em 1960, fundou a firma Ramos Representações Ltda. ampliando suas ações comerciais. Com a expansão do uso do automóvel cresceram as vendas de autos e de acessórios, o que tornou o setor bastante promissor. Em 1963, em sociedade com seus irmãos, criou a Ginjo Autopeças Ltda, distribuidora de peças para automóveis, caminhões e tratores, hoje uma das maiores empresas do País no ramo.

Em localidades do interior paulista, a oportunidade de se tornar correspondente/representante/comissionário de casa comercial já estabelecida, distribuindo e vendendo mercadorias sem grandes investimentos, em consignação ou por comissão, podia significar a realização nos negócios. Entre caixeiros-viajantes, muitos passaram frequentar o interior paulista, viajando de trem e mais tarde, de carro.

É o caso dos irmãos Francisco Pedrão e Antônio dos Santos (nascidos em 1912 e 1921 e aportados no Brasil em 1926 e 1928 respectivamente), naturais de Talhas, Concelho de Macedo Cavalheiros/Trás os Montes. Depois de outras experiências, inclusive de trabalho em padarias, durante décadas foram caixeiros-viajantes da indústria Dox (de origem alemã, estabelecida em 1932, no setor de válvulas e barômetros). Deixaram em suas memórias relatos como viajantes pelos interiores de São Paulo, norte do Paraná, Minas Gerais e Goiás. A princípio iam de trem (carregando os equipamentos e catálogos pesados), depois corriam a clientela com Jipe e Rural Willys, veículos resistentes para enfrentar as estradas de terra. Francisco sempre gostou da função, baseado em Londrina e permanecendo nela até a aposentadoria. Já Antônio dos Santos chegaria à função de gerente-geral da empresa alemã, permanecendo em seus quadros por mais de 50 anos.

Outro exemplo é o de Antônio Lopes Balau, nascido em 1908 em Proença Nova, distrito de Castelo Branco e que chegou ao Brasil já casado, em 1943. Começou como empregado da firma atacadista de secos e molhados J. Pires. Com o tempo, Balau passou a fazer fretes por sua conta: adquiriu um caminhão para entregar o açúcar produzido em Ribeirão Preto e que era vendido no extremo oeste paulista, nas regiões de Fernandópolis, Birigui, Araçatuba, Rancharia e Dracena. Seu sobrinho (que também foi "recrutado" em Portugal aos 13 anos de idade), entrevistado, conta que Balau, para não retornar com o caminhão vazio, passou a comprar madeira, que era abundante nessas regiões recém-abertas à colonização, passando a comercializá-la na região de Ribeirão Preto, onde a demanda era grande. A partir daí, juntou-se com sócios portugueses, já estabelecidos no negócio de madeireiras em Campinas e em 1952 fundou sua empresa. Dois anos depois, chamou seu cunhado de

48 Presidente da Casa de Portugal por várias gestões, de 1985 a 2007 e de 2013 a 2018.

Locus: Revista de história, Juiz de Fora, v.25, n. 2, p.100-120, 2019

E-ISSN: 2594-8296 - ISSN-L: 1413-3024 
Portugal para se juntar ao negócio. Ia cada vez mais longe, à medida que a madeira rareava: Presidente Epitácio, Presidente Prudente, Mato Grosso, norte do Paraná e até Paraguai. Com a prosperidade dos negócios, presidiu a montou uma rede de lojas no interior paulista. Tornou-se liderança da colônia lusitana de Ribeirão Preto, presidindo a Casa de Portugal por 24 anos consecutivos ${ }^{49}$.

\section{Ganharás o pão com o suor de teu rosto}

Nas décadas de 1910 e 1920, bares, botequins, cafés, restaurantes, confeitarias, doceiras e pastelarias se expandiram nas cidades dos interiores de São Paulo, com os portugueses se destacando nesses estabelecimentos de diferentes tipos, alguns oferecendo serviços mais simples, outros mais elaborados e sofisticados. As padarias e confeitarias eram consideradas bons negócios nos quais os portugueses marcaram presença, fazendo vários tipos de pães, fabricando bolachas, doces, recebendo encomendas e também comercializando bebidas, conservas nacionais e estrangeiras.

O "Álbum da Colônia Portuguesa" ${ }^{50}$ aponta várias padarias e destaca que o setor era promissor e se encontrava em expansão. J. Lourenço e Irmão, por exemplo, proprietários de padarias em Santos, instalaram outro estabelecimento do gênero em Campinas, mostrando uma expansão dos negócios e visão comercial, uma vez que Campinas era importante centro regional. Em Ribeirão Preto, Antônio Garcia de Souza, nascido em 1871 em Viseu, tornou-se conhecido como proprietário da Confeitaria Smart, considerada uma das melhores do ramo, o que lhe abriu as portas para ocupar cargos relevantes na Sociedade Portuguesa de Beneficência e na Associação Comercial e Industrial da cidade ${ }^{51}$.

Tratando-se de um setor que exigia muito trabalho, apesar de capital relativamente modesto, não eram muitas as barreiras à entrada no ramo. Em contrapartida, estabelecia-se uma concorrência acirrada, mesmo entre conterrâneos. Algumas padarias ofereciam pão quente desde as 5 horas até as 9 horas pela manhã, entre as 15 e 17 horas e das 19 até as 21 horas. Estas práticas foram difundidas especialmente nas padarias de propriedade dos portugueses, que também inovaram a organização do negócio com a incorporação de vários sócios que se revezavam em diferentes turnos, garantindo o funcionamento dos estabelecimentos 7 dias por semana e por quase 20 horas diárias. Os lusos integravam todas as etapas da produção do pão: donos de padarias, fornecedores de lenha e carvão para os fornos, trabalhavam como masseiros, forneiros, carvoeiros e entregadores ${ }^{52}$.

\footnotetext{
${ }^{49}$ Em função de sua projeção, o próprio governo português o distinguiu como comendador (PRATES, Prisco Cruz. Ribeirão e os seus homens progressistas. Ribeirão Preto: ed. do autor, 1981, p. 21-24).

${ }^{50}$ CARINHAS, Álbum, p. 416-417.

51100 anos da $A C I R P$, p. 233.

52 As informações a seguir sobre o processo de trabalho dos padeiros baseiam-se em: MATOS, Maria I. S. Ganharás o pão com o suor do teu rosto: imigrantes portugueses, padeiros e experiências políticas São Paulo/BR 1870-1945. Revista de
} 
O fazer o pão exigia um conhecimento e habilidades profissionais, subentendendo um processo com diferentes etapas e hierarquias. Inicialmente o trigo era peneirado dentro de uma masseira de madeira, em separado fazia-se o fermento, em seguida misturavam-se os ingredientes que deveriam ser amassados "a muque" (utilizando-se a força física) ${ }^{53}$, só com experiência - através do toque - que se adquiria o conhecimento do ponto ideal da massa.

A massa já pronta descansava, dependendo da temperatura esse processo era mais lento ou mais rápido; posteriormente ela era cortada, pesada, sovada, para depois se modelar os pães, que eram colocados em tábuas aprontando-os para serem levados ao forno; na hora de colocar no forno era que o corte do pão era dado.

O forno de barro e tijolos, redondo, não possuía termômetros, estando sob o controle do padeiro. Nas padarias maiores havia o forneiro, que devia preparar o forno (limpava, colocada à lenha, ascendia o fogo) e pela experiência sentir a temperatura, sabendo o momento exato de colocar e retirar o pão do forno. Os pães eram colocados no forno com cuidado e habilidade, com a palheta posicionando-os de um lado e retirando-os prontos de outro; estas ações exigiam atenção e prontidão para evitar que os pães ficassem crus ou torrados.

A jornada de trabalho nestes estabelecimentos era longa, começava às 18 horas com o preparo da massa, se estendia por toda a noite, já que às 4:30 horas o pão deveria estar pronto para a venda e para as entregas à freguesia. Já às 7 horas, começavam os preparativos para o pão da tarde, quando os instrumentos e o local eram limpos enquanto o pão estava sendo assado. O descanso era das 12 horas ás 18 horas; contudo, este o horário não era fixo podendo ocorrer modificações.

Os padeiros também ajudavam no balcão e realizavam as entregas, mas, em outros casos a "freguesia era feita" pelo entregador, que iniciava o trabalho por volta das 4:30 horas da madrugada e terminava por volta das 6:30 horas. Estes saíam com um cesto grande e entregavam em armazéns, bares e domicílios. Alguns entregadores comercializavam em carrocinhas (puxadas a burro ou cavalo, posteriormente motorizadas) que lhes permitiam servir uma clientela mais distante.

A freguesia era constituída por uma parceria entre o freguês e o padeiro/entregador, que se empenhavam em agradar e manter a clientela. As relações estabelecidas entre eles subentendiam solidariedade e cobranças: várias eram as exigências, quanto à pontualidade de horário na entrega, o tipo e qualidade do pão e as preferências (o pão mais torrado ou branquinho). Mesmo em momentos de dificuldades para a obtenção e controle sobre a farinha de trigo, que poderiam levar à perda de qualidade do pão, os padeiros se empenhavam em servir a freguesia. O pagamento era realizado aos

História da Sociedade e da Cultura, v. 12, p. 417-441, 2012; e MATOS, Maria I. S. Portugueses e experiências políticas: a luta e o pão: São Paulo 1870-1945. História (UNESP), v. 28, p. 150-176, 2009.

53 As masseiras elétricas começaram a ser utilizadas em meados da década de 1920, mas sua difusão foi lenta e parcial, sua incorporação mais generalizada, ocorreu a partir dos anos 1940.

Locus: Revista de história, Juiz de Fora, v.25, n. 2, p.100-120, 2019

E-ISSN: 2594-8296 - ISSN-L: 1413-3024 
sábados, mas havia os que "acertavam" por quinzena e até por mês; logicamente, havia os atrasos e dívidas acumuladas.

O pão tinha que ser feito todos os dias, sendo imperdoável a falta do padeiro e não havendo descanso, sábados, domingos ou feriados. Para além da jornada extensa e noturna, sem repouso e da falta de folgas, deve-se destacar que todas as etapas do processo de preparação do pão eram árduas e pesadas, com dispêndio de força para a preparação da massa, além das altas temperaturas do local de trabalho. A esta situação somava-se a insalubridade da função que causava mal aos pulmões e aos olhos, doenças cardíacas e pulmonares, como tuberculose, asma e pneumonia, além de reumatismo, queimaduras e varizes.

Nesta atividade os ganhos eram parcos, alguns trabalhavam por anos sem receber nada a não ser a hospedagem e um prato de comida. Mesmo para os mais gabaritados, os pagamentos eram instáveis, sendo que alguns ampliavam os ganhos com a venda do pão em domićlío.

A maior parte dos trabalhadores das padarias (homens solteiros) morava no local de trabalho, uma espécie de alojamento provido pelo proprietário, que também fornecia as refeições, o que facilitava a admissão de imigrantes recém-chegados, livrando-os das despesas com acomodações, transporte e alimentação. Contudo, os cômodos eram precários, sujos, mal arejados e a comida não podia ser considerada boa. Cabe observar que essas ações eram estratégias patronais de controle sobre o cotidiano e o horário de trabalho, ao procurar garantir assiduidade, pontualidade e possibilidade de extensão da jornada, buscando também disciplina, criando dependência e outros vínculos.

O dono da padaria - o português - escolhia o padeiro e seus ajudantes, fornecia o local e a matéria prima e cobrava produção. Buscava o controle, através do número de pães que cada saca de trigo produzia, apesar de que esse número dependia da qualidade da farinha e das habilidades do padeiro. Também, controlava a produção, através da vigilância do processo de trabalho, chegando a trancar a sala da padaria para restringir a saída dos trabalhadores.

Aprendia-se a ser padeiro na própria padaria. Os jovens principiantes observavam o processo de preparação do pão atuando como auxiliares, alguns entravam com 8, 10 anos, eram filhos, parentes ou amigos do próprio padeiro ou do dono da padaria. O processo de aprendizagem era lento, incluindo submeter-se a várias atividades: peneirar o carvão, rachar lenha, colocar lenha no forno, limpar o forno, carregar os sacos de farinha, enrolar os panos, ajudar a fazer a massa, limpar e varrer a padaria, atender no balcão e fazer entregas. Eram atividades que demandavam força: aguentar peso, carregar o cesto com 60 pães, conhecer as redondezas e a freguesia, enfrentar a longa jornada, entre outras. Dependendo das habilidades e dedicação, os aprendizes poderiam passar para amassador, padeiro e forneiro. 
Da mesma forma que em outros ramos comerciais, observa-se que os imigrantes ao chegar contavam com o apoio dos parentes ou conterrâneos já radicados, sendo prática comum mandar chamar parentes, conhecidos, jovens da aldeia, todos considerados de confiança, para ajudar nos negócios. Mas cabe lembrar que em alguns casos a ajuda se transformava em exploração do trabalho desses jovens e pobres, desprotegidos em ambiente desconhecido, coexistindo assim exploração e paternalismo.

Os aprendizes e padeirinhos trabalhavam em troca de casa e comida, numa rotina que incluía limpeza da padaria, atendimento dos fregueses nos balcões, estoques, carregar e entregar mercadorias. Buscando formar trabalhadores produtivos, obedientes e dóceis, patrões e mestres impunham práticas austeras, medidas destinadas a inculcar nas crianças hábitos de trabalho, hierarquias, disciplina que podiam incluir castigos físicos, punições aviltantes e violentas e outras práticas vexatórias, como dormir debaixo dos balcões ou no ladrilho da padaria, o que tornava as fugas frequentes.

O balcão da padaria era também um palco das tensões do cotidiano envolvendo cobranças, atrasos e recusa no pagamento das contas consideradas abusivas, hostilidades, brigas, provocações, insultos, xingamentos e manifestações de antilusitanismo.

$\mathrm{Na}$ trama destas relações se destacam os vínculos de nacionalidade e memórias em comum, a ajuda aos conterrâneos na hora da chegada, hospedagem e empréstimos, também o estabelecimento de relações de confiança (gerência e até sociedade nos negócios), favores e dependências. Mas, principalmente, de tensões. Afinal, era o dono da padaria - o português - que escolhia o padeiro e seus ajudantes (também portugueses), sempre buscando manter o controle e a sujeição dos trabalhadores.

\section{Considerações finais}

A busca pela visibilidade dos portugueses nos interiores de São Paulo implicou num trabalho árduo de pesquisa frente às dificuldades de acompanhar os rastros e as trajetórias desses imigrantes. Durante a investigação pôde-se recuperar a presença, observando atividades econômicas nas quais os portugueses mostraram-se atuantes. Os imigrantes portugueses passaram por diferentes experiências de trabalho tanto nas fazendas de café e colônias, como nas cidades. Alguns conseguiram rendas relativas e ascensão social, outros se mantiveram remediados e/ou apenas sobreviveram. Apesar desta diversidade, o trabalho tornou-se um elemento estratégico para concretizar o desejo do sucesso, ajudando a superar os medos e inseguranças, sendo capaz de conferir coerência e sentido, construindo laços de solidariedade.

O trabalho perpassou a experiência histórica desses imigrantes; junto com a família e a religião, tornou-se fator de identificação do grupo, que se auto representava como "trabalhadores, honestos e 
- MARIA IZILDA S. MATOS

E OSWALDO TRUZZI

poupadores", sendo capazes de suportar dificuldades e com despojamento entregar-se à faina de corpo e alma. As mulheres, igualmente, desempenharam um papel ativo no cotidiano de trabalho e nos negócios, participando das decisões familiares e mantendo as tradições.

Apesar do empenho destes escritos em dar visibilidade aos imigrantes portugueses, questionando os ocultamentos e premissas impostas pela historiografia, ainda restam muitas inquietações que se mantêm latentes como possibilidades de desdobramentos em outras investigações.

Recebido: 21 de julho de 2019

Aprovado: 12 de outubro de 2019 